\title{
Application and comparison of stability analysis of slope using circular arc method and strength reduction method
}

\author{
Bin Bin $X U^{1, a}$, Lin Bo XIE ${ }^{1}$ and Wei SI ${ }^{2}$ \\ 1 Tianjin Port Engineering Institution Ltd. of CCCC.; Key Lab. of Geotechnical Engineering of Tianjin; Key Lab. of Geotechnical \\ Engineering, Ministry of Communication, Tianjin 300222, China \\ ${ }^{2}$ Tianjin Port Engineering Institution Ltd. of CCCC.; Tianjin 300222, China
}

\begin{abstract}
In order to evaluate the accuracy of strength reduction method using FEM, the safety factors of the uniform clay slope and sand slope are investigated by Fellenius's method, Bishop's method using traditional limit equilibrium method and strength reduction method respectively. The limit equilibrium method is carried out based on the code for foundations in port engineering and the FE analysis is based on Plaxis $3 \mathrm{D}$. The results show that the safety coefficient obtained by strength reduction method of FEM is larger than that obtained by limit equilibrium method and the errors are $6.03 \%$ and $1.61 \%$ for clay slope and $8.54 \%$ and $3.99 \%$ for sand slope.
\end{abstract}

\section{Research background}

The side slope comes into being artificially or naturally and its destructional form is usually slide or collapse of the slide. The slope can be classified into natural slope and artificial slope by genesis, or soil slope and rock slope by composition, or high slope and general slope by height, or temporary slope and permanent slope. The reason of destruction can be attributed to two categories: the equilibrium of the stress state of the slope is disturbed by external actions; the strength of the slope soil is reduced by external influence. As the infrastructure construction such as irrigation works, transportation, mining develops, more and more engineers are related to the slope stability. How to evaluate the safety coefficient becomes the key point for the design, construction, controlling of the slope.

The limit equilibrium method is the main method for the stability analysis of the slope, which is based on the Coulomb's and Ranking's earth pressure. The characteristics of the limit equilibrium method only consider the static equilibrium condition and Mohrcoulomb's principle, namely analysing the equilibrium of the soil at destruction. During the analysis of the slope stability the plane strain condition is usually assumed and the sliding surface is regarded as artificial arc surface in early researches. The safety coefficient of the slope is defined by the ratio of anti-slide action to the slide action. In modern engineering, the concept of safety stock of the strength index is well admitted. Namely, the strength index of soil is reduced simultaneously until there is slide surface at the limit equilibrium state.

\section{General methods for stability analysis}

During the development of the slope research, lots of calculation methods of the safety coefficients have been proposed. In 1916, the Swedish method is proposed by Fellenius and Taylor ${ }^{[1]}$, which is the earliest method for the slope stability analysis. In this method, the sliding surface is supposed to be arc and the positive slide force is on the tangent direction of the weight in the calculation. Supposing that there are many sliding surfaces and each sliding surface corresponds to one safety coefficient, the smallest safety coefficient is regarded as the final safety coefficient of the slope and it can be expressed as :

$$
F_{S}^{i}=\frac{M_{f}^{i}}{M_{i}}
$$

where $F_{S}^{i}$ represents the safety coefficient of the ith sliding surface, $M_{f}^{i}$ is the anti-sliding moment of the ith sliding surface to the upper sliding volume and $M_{i}$ is the sliding surface of the upper sliding volume, and the final safety coefficient $F_{S}=\min \left(F_{S}^{i}\right)$.

In 1955 , Bishop ${ }^{[2]}$ proposed another simplified method based on the Swedish method in which the arcshape slide surface and the equilibrium of the moment are kept while the interaction between two strips is considered. The safety coefficient is represented by the ratio between the resistant shear strength and the actual shear strength on the sliding surface, which is called safety factor of shear stress :

\footnotetext{
${ }^{\mathrm{a}}$ Corresponding author: xubinbin@tpei.com.cn
} 


$$
F_{S}=\min \left(F_{S}^{i}\right)=\min \left(\frac{\tau_{f}}{\tau}\right)=\min \left(\frac{\boldsymbol{c}_{f}+\sigma \tan \varphi_{f}}{\tau}\right)
$$

Here, $i$ and $S$ have the same physical meaning.

Besides, other shapes of the sliding surface instead of the arc surface are also used to compute the safety coefficients such as simplified Janbu method. Based on satisfaction of the equilibrium of the moment and the force, Morgenstern and Price ${ }^{[3]}$ proposed a strict deduction of safety analysis assuming arbitrary shape of sliding surface.

Although there are a lot of definitions for the strength reduction method of $\mathrm{FEM}^{[4-8]}$, the principle is almost the same. Ducan ${ }^{[9]}$ pointed out that the safety coefficient can be defined as the reduction extent of the shear strength when the slope reaches the critical destroy state, which can be regarded as the strength reservation. The points of the strength reduction method is that the shear strength of the soil are reduced simultaneously assuming the external force keeps constant and then the finite element analysis is carried out to analyse the stress and strain until the destruction of the slope. Zhao and Zheng ${ }^{[10]}$ believed that the safety coefficients obtained by Bishop method and strength reduction method possess the same physical meaning and the essential of two methods are also same.

\section{Results by limit equilibrium method}

In this chapter, the safety coefficient of the slope would be calculated by the Fellenius's method and Bishop's method which are the traditional limit equilibrium method. The slope is assumed to be composed by uniform soil and the detailed coordinates at each point are also shown in Fig. 1. The gradient of the slope is $1: 2$ and the underground level is below the ground about $20 \mathrm{~m}$.
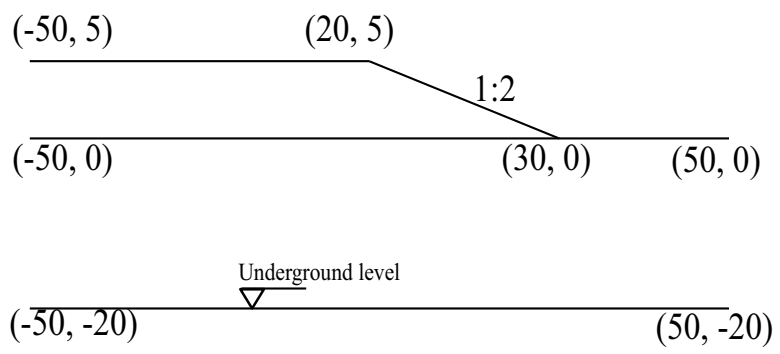

Figure 1. Sketch of the simple slope

The composition of the slope is regarded as clay or sand respectively. The soil parameters are listed in Table 1. As can be seen, the bulk densities of both clay and sand are the same. The cohesive force of clay is larger than that of sand while the frictional angle of clay is smaller than that of sand.

Table 1. Soil parameters of clay and sand

\begin{tabular}{|c|c|c|}
\hline & Clay & Sand \\
\hline Bulk density & $18 \mathrm{kN} / \mathrm{m}^{3}$ & $18 \mathrm{kN} / \mathrm{m}^{3}$ \\
\hline Cohesive force & $10 \mathrm{kPa}$ & $1 \mathrm{kPa}$ \\
\hline Frictional angle & $20^{\circ}$ & $30^{\circ}$ \\
\hline
\end{tabular}

The calculation is carried out by the computation system for port engineering which is developed by Tianjin port engineering institute. It is written by Fortran program based on Code for foundations in port engineering. It can deal with the settlement of the ground, vertical and horizontal consolidation, bearing capacity, slope stability. The calculation results are listed in Table 2 using each method for the uniform clay slope and sand slope. As can be seen, the safety coefficient of the clay is 1.84 and 1.92 determined by Fellenius's method and Bishop's method and the safety coefficient of the sand is 1.37 and 1.43 respectively. The safety coefficient obtained by Fellenious's method is smaller than that obtained by Bishop's method, which can be ascribed to that the interaction force between two slices is taken into consideration.

Table 2. Safety coefficient of the slope using limit equilibrium method

\begin{tabular}{|c|c|c|}
\hline & Clay & Sand \\
\hline Fellenius & 1.84 & 1.37 \\
\hline Bishop & 1.92 & 1.43 \\
\hline
\end{tabular}

\section{Results by strength reduction method}

Although the strength reduction method has been widely used in the stability analysis of the slope, the final safety coefficient is always depended on the evaluation criterion of instability. Usually the numerical convergence is taken as the judge criterion, but the influence factors of the convergence of FEM are multiple and it is difficult to explain whether the divergency is attributed to instability or not. Now there are mainly three judge criterions for the instability of the slope: convergence of calculation, runthrough of the plastic range and sudden change of characteristic position.

When using strength reduction method for the slope stability, the calculation convergence is usually used as the criterion ${ }^{[11-13]}$. If the convergent solution cannot be obtained under the designated convergence judgment, the slope loses its stability. For the run-through of the plastic range, some significant shear bands have been observed during the damage of the slope. Similar regulation can be forecasted. If there is run-through plastic deformation in the slope under certain reduction coefficient, such a coefficient can be regarded as the safety coefficient. For the sudden change of characteristic position, the treatment is building the relationship between the displacement of certain point and the reduction coefficient in the FE calculation. If there is a sudden change in the curve, the slope is in a critical state.

A FE code called Plaxis3D is used to carry out the strength reduction method. In Plaxis3D, a module called safety analysis can be used for the slope stability analysis. In the calculation, the reduction coefficient is gradually reduced and the total displacement at toe of the slope is also monitored for each reduction coefficient. When the relationship between the reduction coefficient and the 
total displacement is plotted in the diagram, the safety coefficient is taken as the reduction coefficient if there is no variation even though the total displacement increases. The finite element mesh is shown in Fig. 2 and the variation of reduction coefficient of clay slope and sand slope is shown in Figs. 3 and 4. The four side surfaces are restricted on the nominal direction and bottom surface is restricted at both the horizontal and vertical direction. The hydraulic condition is the same as that in the limit equilibrium method.

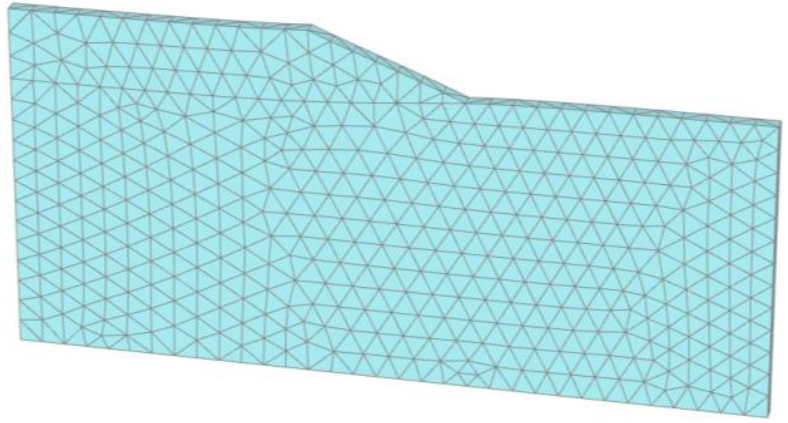

Figure 2. Finite element mesh

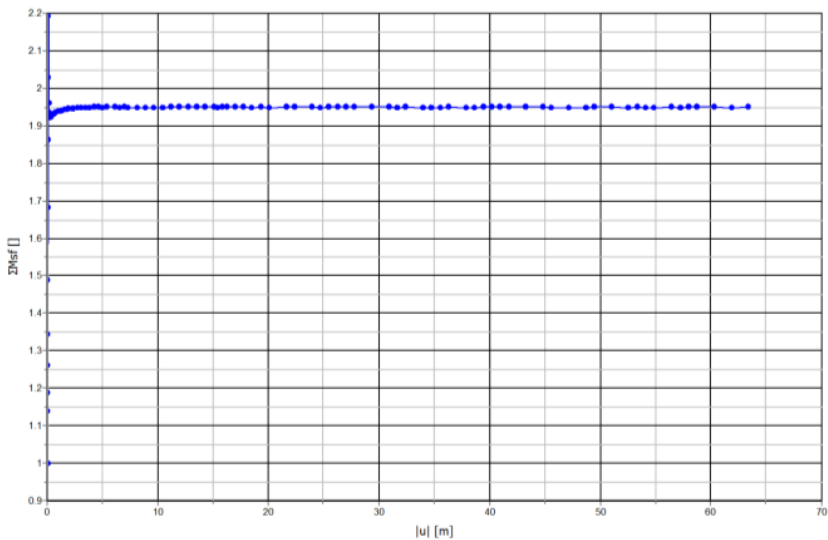

Figure 3. Variation of reduction coefficient of clay slope

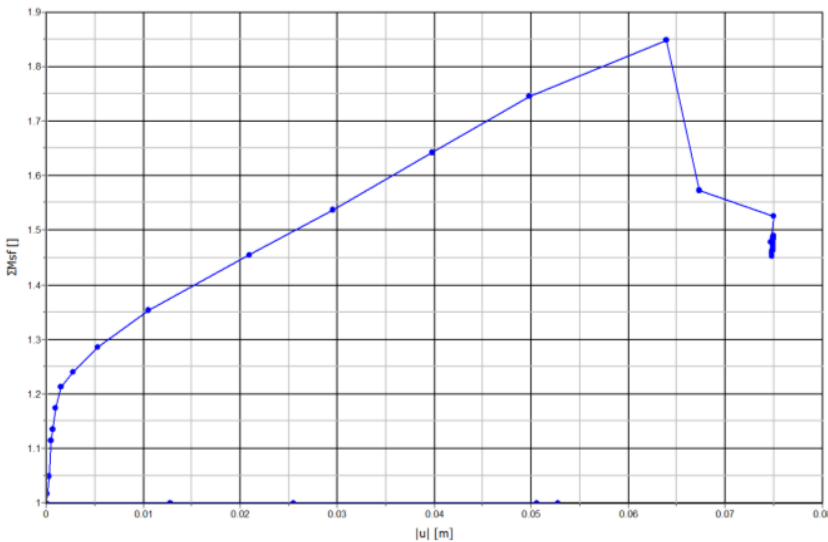

Figure 4. Variation of reduction coefficient of sand slope

As have been explained above, the method to determine the safety factor is to see whether the final reduction coefficient is constant or not as the total displacement of characteristic point increases. The variation of the reduction coefficient of the clay slope is shown in Fig. 3. As can be seen, the reduction factor firstly increases to as large as 2.2 and then decreases to
1.951. Therefore, the safety factor of the clay slope is 1.951. Similarly, the safety factor of the sand slope is shown in Fig. 4. The final reduction factor keeps 1.487. All in all, the reduction coefficients of clay slope and sand slope keep constant as the total displacement increases and the safety coefficients of the clay slope and sand slope obtained by strength reduction method are 1.951 and 1.487 respectively. Taking the safety coefficients obtained by traditional limit equilibrium method into consideration, the safety coefficients of clay and sand slopes are listed in Table 3. The safety coefficient obtained by strength reduction method of FEM is larger than that obtained by limit equilibrium method and the errors are $6.03 \%$ and $1.61 \%$ for clay slope and $8.54 \%$ and $3.99 \%$ for sand slope. There seems to be a fact that the clay slope is more suitable for strength reduction method because the errors are smaller.

Table 3 Safety coefficient of slope using different method

\begin{tabular}{|c|c|c|}
\hline & Clay & Sand \\
\hline Fellenius & 1.84 & 1.37 \\
\hline Bishop & 1.92 & 1.43 \\
\hline FEM & 1.951 & 1.487 \\
\hline Error to Fellenius & $6.03 \%$ & $8.54 \%$ \\
\hline Error to Bishop & $1.61 \%$ & $3.99 \%$ \\
\hline
\end{tabular}

In addition, Figs. 5 and 6 present the settlement of the ground and the slope. Initially, the ground stress is added to the finite element model and the settlement of the ground is zero, as shown in Fig. 4. Then the slope is regarded as an embankment to the ground and significant settlement occurs in the ground. The safety analysis of the slope is then carried out and the occurred settlement should be removed before the stability analysis. From the finite element analysis, we can see that the strength reduction analysis is easier to be understood because the entire process of the deformation can be monitored.

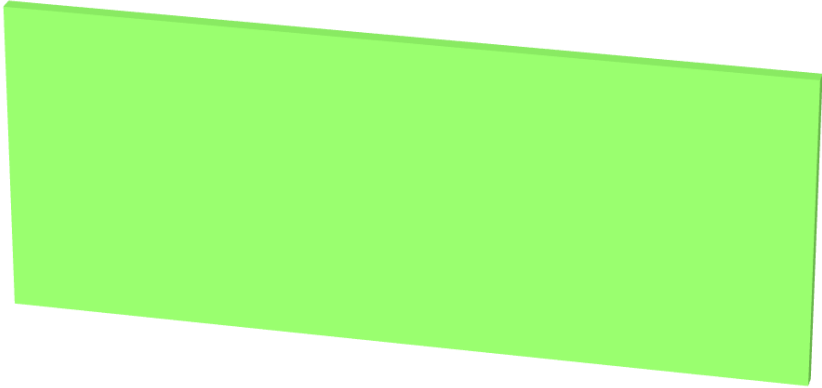

Figure 5. Initial state of the ground 


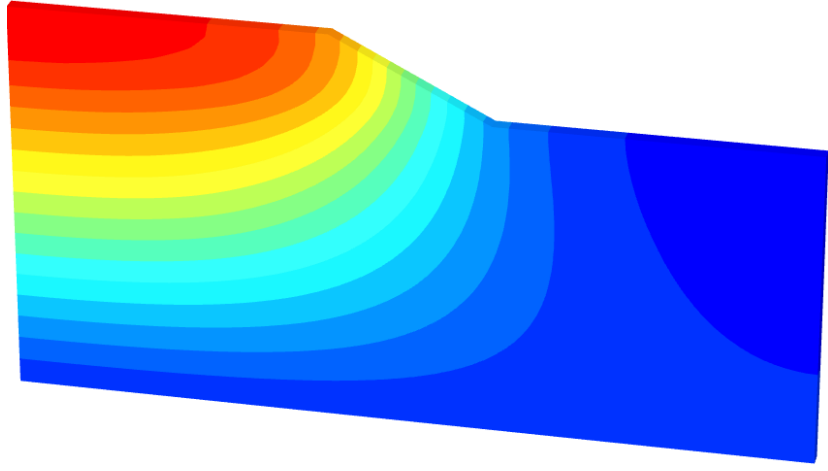

Figure 6. Settlement of the ground

After the safety analysis, the possible sliding surface can be shown by chosing the contour of total incremental displacement. The slide surfaces of the clay slope and the sand slope are shown in Figs. 7 and 8 respectively. The slide surface of the clay goes through the inside of the slope and the toe of the slope, which is in accordance with the traditional analysis method. While for the sand slope, the slide surface lies at the side surface of the slope. Actually, in Plaxis3D the plastic computation becomes very complex as the friction angle increases.

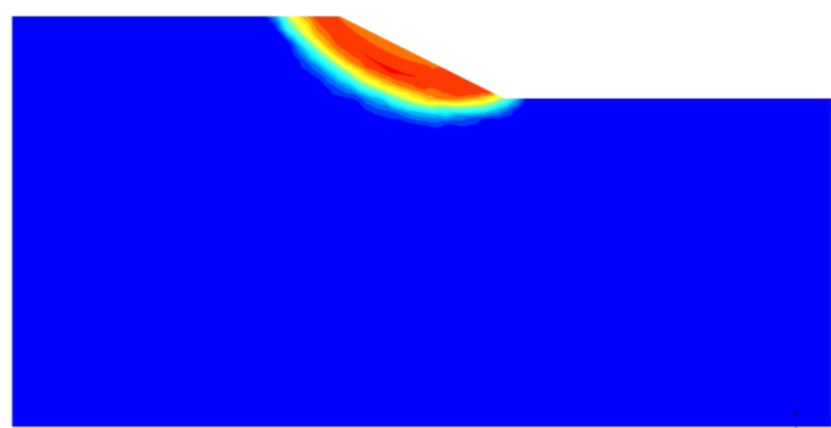

Figure 7. Slide surface of the clay slope

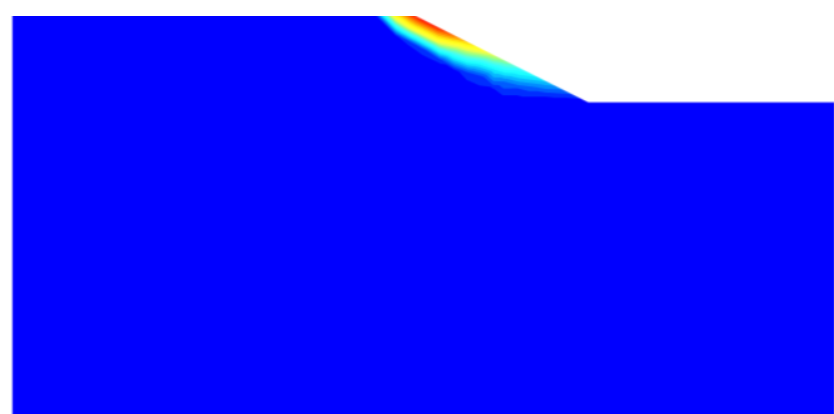

Figure 8. Slide surface of the sand slope paper, the safety factors of one uniform clay slope and sand slope are firstly calculated by Fellinius's method and Bishop's method, which are then compared with the safety factor obtained from strength reduction method by FEM. The conclusions are as follows:

1) The safety coefficient of the clay slope is 1.84 and 1.92 determined by Fellenius's method and Bishop's method and the safety coefficient of the sand slope is 1.37 and 1.43 respectively.

2) The safety coefficient obtained by Fellenious's method is smaller than that obtained by Bishop's method, which can be ascribed to that the interaction force between two slices is taken into consideration.

3) The reduction factor firstly increases to as large as 2.2 and then decreases to 1.951 and the safety factor of the clay slope is 1.951 .

4) The safety coefficient obtained by strength reduction method of FEM is larger than that obtained by limit equilibrium method and the errors are $6.03 \%$ and $1.61 \%$ for clay slope and $8.54 \%$ and $3.99 \%$ for sand slope.

5) There seems to be a fact that the clay slope is more suitable for strength reduction method because the errors are smaller.

\section{References}

1. W. Fellinius, Int. Cong. of Large Dams, Washington, 4445 (1936)

2. A.W. Bishop, Geotechnique, 5, 7 (1955)

3. N.R. Morgenstern, Geotechnique, 15, 11 (1965)

4. N. Janbu, Proc. of Eur. Conf. on Stability of Earth Slopes, Swenden, 3, 43 (1954)

5. E. Spencer, Geotechnique, 17, 1 (1967)

6. N.R. Morgenstern, V.E. Price, Geotechnique, 15, 79 (1965)

7. Z. Chen, N.R. Morgenstern, Canadian Geotechnical Journal, 20, 104 (1983)

8. I. Donald, Z.Y. Chen, Canadian Geotechnical Journal, 34, 853 (1997)

9. J.M. Duncan, Journal of Geotech. Engineering, (1996)

10. S.Y. Zhao, Y.R. Zheng, China Geotech. Engineering, (2002)

11. K. Ugai, Soils and Foundations, 29, 190 (1989)

12. D.V. Grifiths, P.A. Lane, Geotechnique, 49, 387 (1999)

13. E.M. Dawson, W.H. Roth, Geotechnique, 49, 835, (1999)

\section{Conclusions}

The stability of the slope is always the highlight of geotechnical engineering. Formerly, the limit equilibrium method is widely used due to its clear physical meaning and simple calculation. With the development of the finite element method, the strength reduction method is gradually recognized to determine the safety factor of complex ground. However, the accuracy of the strength reduction method is suspicious because the friction angle and cohesive force are reduced simultaneously. In this 